\title{
FURTHER STUDIES ON THE BIOSYNTHESIS OF CHLOROTHRICIN
}

\author{
Jung J. Lee ${ }^{a}, c$, Jonathan P. LeE ${ }^{a}$, Paul J. Keller ${ }^{a}$, Charles E. Cottrell ${ }^{b}$, \\ Ching-Jer ChAng $^{\mathrm{e}}$, Hans ZäHNer ${ }^{\mathrm{d}}$ and Heinz G. Floss ${ }^{\mathrm{a}}$ \\ ${ }^{\mathrm{a}}$ Department of Chemistry, ${ }^{\mathrm{b}}$ Campus Chemical Instrument Center, Ohio State University, \\ Columbus, Ohio, U.S.A. \\ ${ }^{\mathrm{c} D e p a r t m e n t}$ of Medicinal Chemistry and Pharmacognosy, Purdue University, \\ W. Lafayette, Indiana, U.S.A. \\ ${ }^{\mathrm{d}}$ Lehrstuhl für Mikrobiologie I, University of Tübingen, \\ West Germany
}

(Received for publication March 22, 1986)

\begin{abstract}
Feeding experiments with $\left[U-{ }^{13} \mathrm{C}_{3}\right]-$ and $(2 R)-\left[1-{ }^{2} \mathrm{H}_{2}\right]$ glycerol showed that glycerol is incorporated intact into carbon atoms 22,23 and 24 of the aglycone of chlorothricin. C-1 of glycerol gives rise to $\mathrm{C}-22$ with retention of one atom of deuterium, which occupies the $\mathrm{H}-22 \mathrm{R}$ position. A mechanism for the assembly of the aglycone is proposed which invokes phosphoenolpyruvate as the direct precursor of the 3-carbon moiety and a Baeyer-Villiger oxidation as the mode of formation of the macrocyclic lactone functionality. A feeding experiment with $\left[1,2-{ }^{13} \mathrm{C}_{2}\right]$ succinate suggests that the propionate units of the aglycone polyketide are formed entirely via the methylmalonyl-CoA mutase reaction. The formation of the two 2,6-dideoxy-D-rhamnose moieties of chlorothricin from glucose was shown to involve replacement of the 2-hydroxyl group of the sugar by hydrogen with inversion of configuration at $\mathrm{C}-2$. This contrasts with the retention stereochemistry observed earlier for the analogous formation of the 2,6-dideoxyhexose moiety of the antibiotic granaticin.
\end{abstract}

Chlorothricin (I) is an unusual macrolide antibiotic produced by Streptomyces antibioticus ${ }^{1 \sim 5)}$. Its structure consists of three types of components, a modified 6-methylsalicylic acid, two identical 2,6-dideoxyhexose moieties and the aglycone, chlorothricolide (II). Earlier biosynthetic studies ${ }^{6,7)}$ have established the biosynthetic origin for most of the carbon frameworks of these components, as summarized in Scheme 1. The modified 6-methylsalicylic acid comes from 4 acetate-malonate units via the polyketide pathway, with contribution of the additional $O$-methyl group by methionine, and the two 2,6-dideoxyhexose moieties are derived directly from glucose. The aglycone is predominantly of polyketide origin, being made up of ten acetate and two propionate units which account for all but three carbon atoms of chlorothricolide. While carbon atoms 25 and 26 of the tetronic acid moiety are derived from an intact acetate unit ${ }^{7}$, C-24, C-23 and the adjacent C-22 are not labeled by either acetate or propionate. The origin of these three carbon atoms, and with it the overall mode of formation of chlorothricolide, is the subject of this paper. In addition, we report on the metabolic route by which the propionate units are generated from primary metabolites, and on a stereochemical aspect of the conversion of glucose into the 2,6-dideoxyhexose moieties.

\section{Results}

Precursor of the Three Missing Carbon Atoms

In our previous publication ${ }^{7)}$ we had hypothesized that carbon atoms 22,23 and 24 of chlorothricolide originate from a molecule of oxalacetic acid which undergoes $\beta$-decarboxylation. However, a feeding experiment with $\left[1,4-{ }^{13} \mathrm{C}_{2}\right]$ succinic acid, expected to be a direct precursor of oxalacetic acid, 
Scheme 1. Biosynthetic origin of chlorothricin.
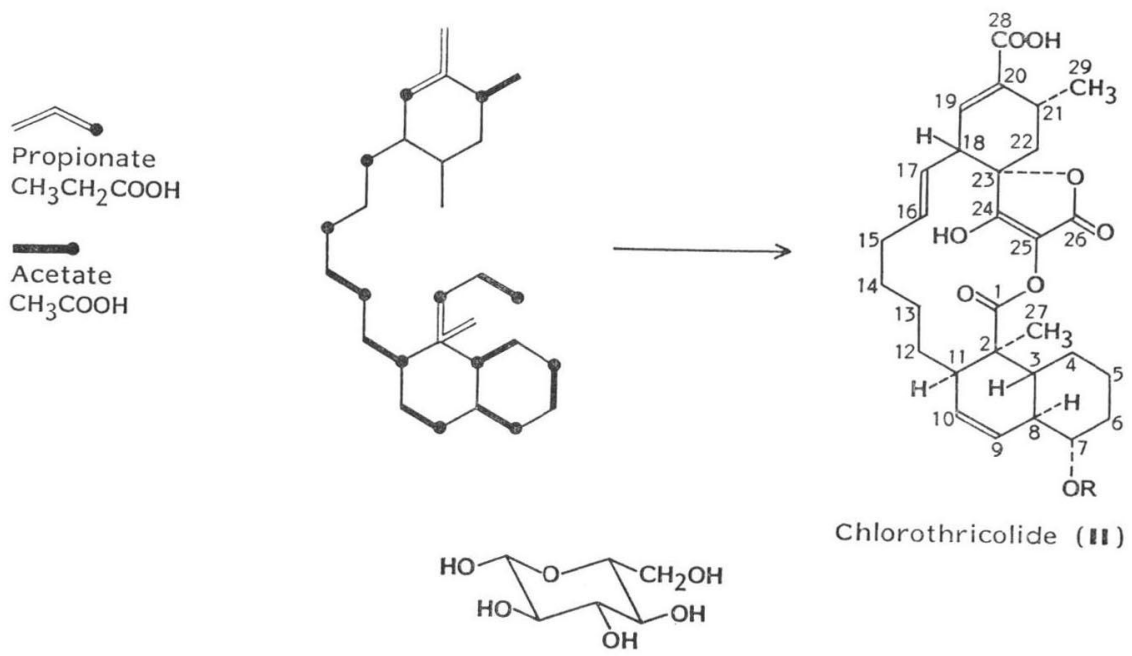

Chlorothricolide (II) $\mathrm{R}=\mathrm{H}$

Glucose
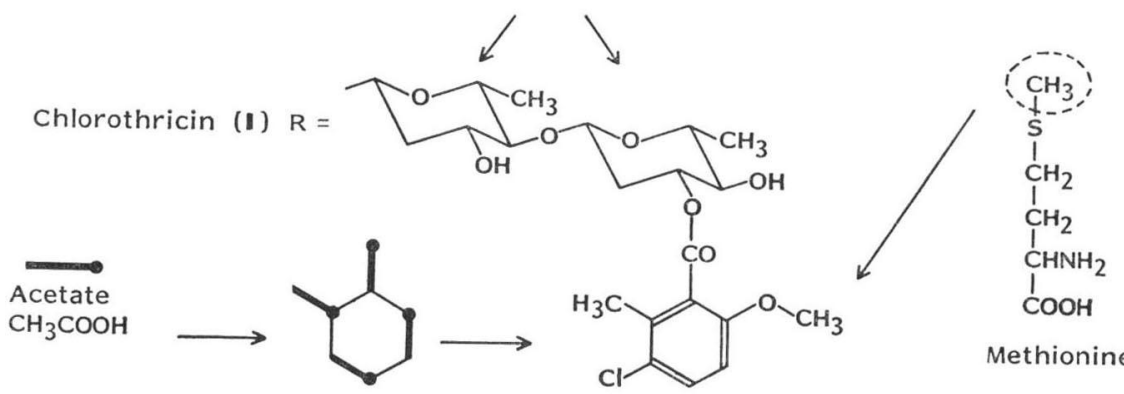

Methionine

gave incorporation only into $\mathrm{C}-1$ and $\mathrm{C}-19$, the same carbon atoms enriched by $\left[1-{ }^{13} \mathrm{C}\right]$ propionate. C-24 was clearly not labeled by this precursor. It was therefore necessary to gain some idea as to the general metabolic origin of these three carbon atoms by carrying out feeding experiments with various ${ }^{14} \mathrm{C}$-labeled compounds. A problem with this approach is that most potential precursors are readily metabolized to acetate and thus show extensive incorporation into the polyketide moiety, masking any specific incorporation into carbons 22,23 and 24. A degradation of the molecule to carve out C-22, C-23 and C-24 selectively would be very cumbersome and was therefore judged impractical. Instead, the following approach was used to obtain a rough measure of the degree of incorporation into parts of the aglycone other than the acetate-derived portion. Methanolysis of the radioactive antibiotic (Scheme 2) gave the aglycone as its methyl ester, methyl 2-deoxyrhamnoside and methyl 2-deoxy-3-O-acylrhamnoside ${ }^{1)}$. The latter was further hydrolyzed to the free acid and methyl 2deoxyrhamnoside. The acyl moiety has been shown to be derived from 4 acetate units and the aglycone contains a polyketide chain of 10 acetate and 2 propionate units. Hence, from the specific radioactivity of the acyl moiety one can roughly estimate what percentage of the radioactivity of the aglycone is located in the 10 acetate-derived carbons, assuming that all acetate units incorporated into the molecule have about the same specific radioactivity. The rest of the radioactivity of the aglycone must be located in the two propionate units and in C-22, C-23 and C-24. 
Scheme 2. Methanolysis of chlorothricin.
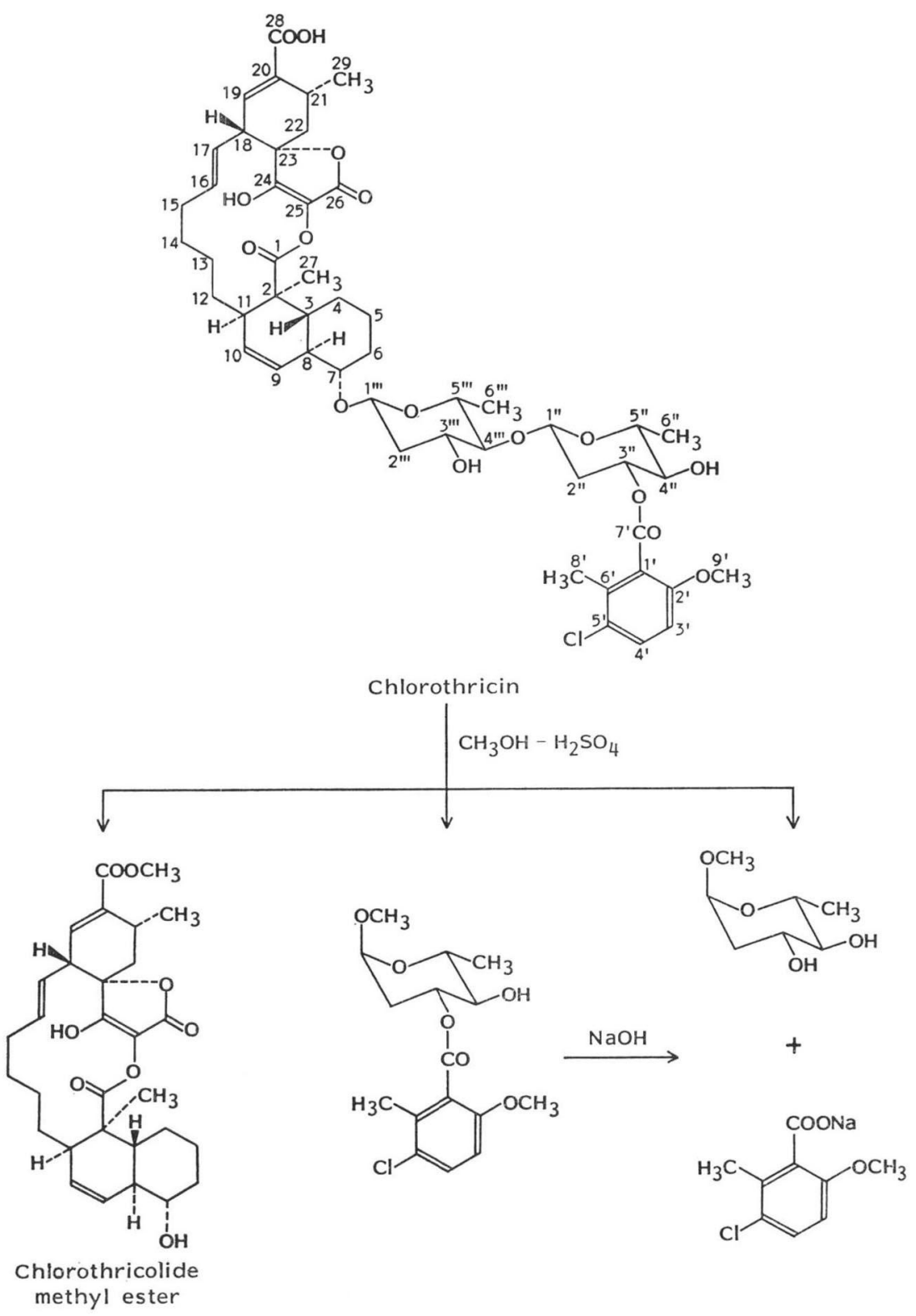

Among a large number of radioactive compounds tested in order to identify a more specific precursor of the missing three carbon atoms (data not shown), in particular $\left[U-{ }^{14} \mathrm{C}\right]$ pyruvic acid and $\left[1-{ }^{14} \mathrm{C}\right]$ lactic acid were found not to be specifically and/or efficiently incorporated. On the other hand, $\left[2-{ }^{14} \mathrm{C}\right]$ glycerol was an efficient precursor of chlorothricin, and the degradation indicated that a sizeable fraction of the radioactivity was located in carbon atoms of the aglycone other than those derived from acetate. To test whether glycerol is incorporated specifically into C-22, C-23 and C-24 as an intact 3-carbon unit, we synthesized $\left[U_{-}{ }^{13} \mathrm{C}_{3}\right]$ glycerol $\left(99 \%{ }^{13} \mathrm{C}\right.$ per carbon). This material (240 $\mathrm{mg}, 2.61 \mathrm{mmol})$ together with $\left[2-{ }^{14} \mathrm{C}\right] \mathrm{glycerol}(18.7 \mu \mathrm{Ci})$ was fed to ten $100 \mathrm{ml}$ cultures of $S$. antibioticus Tü 99, which were harvested 24 hours later to give $130 \mathrm{mg}$ of I. The specific radioactivity of I 
Table $1 .{ }^{13} \mathrm{C}$ Abundances in chlorothricolide methyl ester derived from $\left[U_{-}{ }^{13} \mathrm{C}_{3}\right]$ glycerol (natural abundance $=1.1 \%$ ).

\begin{tabular}{|c|c|c|c|}
\hline Carbon No. & $\begin{array}{c}\text { Chemical } \\
\text { shift (ppm) }\end{array}$ & ${ }^{1} J_{\mathrm{cc}}(\mathrm{Hz})$ & $\begin{array}{l}{ }^{13} \mathrm{C} \text { Abun- } \\
\text { dance }(\%)\end{array}$ \\
\hline$\overline{C-1}$ & 177.7 & & 1.70 \\
\hline $\mathrm{C}-2$ & 47.7 & & 1.30 \\
\hline C-3 & 37.8 & 33.9 & 2.40 \\
\hline C-4 & 26.8 & 33.9 & 2.68 \\
\hline C-5 & 24.3 & 31.5 & 2.97 \\
\hline C-6 & 36.5 & 31.5 & 2.73 \\
\hline C-7 & 73.6 & 34.8 & 2.79 \\
\hline C-8 & 45.7 & 34.8 & 2.60 \\
\hline C-9 & 123.3 & 68.3 & 2.34 \\
\hline C-10 & 130.2 & 68.3 & 2.42 \\
\hline C-11 & 47.0 & 33.5 & 2.50 \\
\hline C-12 & 33.3 & 33.5 & 2.74 \\
\hline C-13 & 28.2 & 43.2 & 2.50 \\
\hline C-14 & 28.6 & 43.2 & 2.31 \\
\hline C-15 & 32.4 & 42.7 & 2.83 \\
\hline C-16 & 138.2 & 42.7 & 2.54 \\
\hline C-17 & 124.7 & 42.6 & 2.61 \\
\hline C-18 & 46.2 & 42.6 & 2.92 \\
\hline C-19 & 136.6 & & 2.12 \\
\hline C-20 & 134.3 & & 1.81 \\
\hline C-21 & 27.4 & 34.0 & 3.16 \\
\hline C-22 & 35.3 & 37.0 & 2.95 \\
\hline C-23 & 80.6 & $\begin{array}{l}37.0 \\
51.3\end{array}$ & 2.12 \\
\hline C-24 & 159.5 & 51.3 & 2.54 \\
\hline C-25 & 115.8 & 91.3 & 1.60 \\
\hline$C-26$ & 165.0 & 91.3 & 2.30 \\
\hline C-27 & 17.1 & & 2.12 \\
\hline C-28 & 166.6 & & 1.65 \\
\hline C-29 & 20.9 & 34.0 & 2.74 \\
\hline $\mathrm{C}-30\left(\mathrm{COOCH}_{3}\right)$ & 51.7 & & 1.10 \\
\hline
\end{tabular}

Fig. 1. Expansions of the signals for C-22, C-23 and $\mathrm{C}-24$ in the ${ }^{13} \mathrm{C}$ NMR spectrum of chlorothricolide methyl ester derived from $\left[U-{ }^{13} \mathrm{C}_{3}\right]$ glycerol.

$$
\text { C- } 24
$$

159. 5 ppm

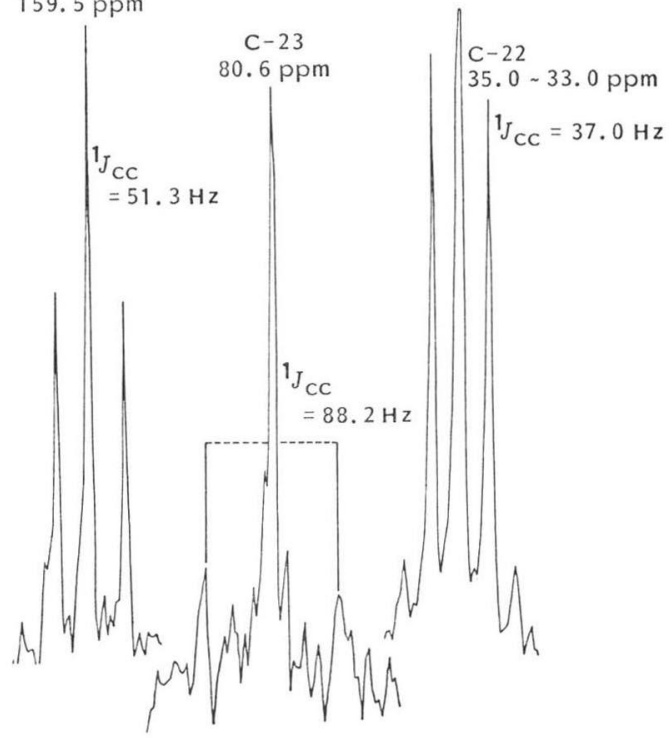

corresponded to an overall specific incorporation of $33.7 \%$. Methanolysis of I gave $49.5 \mathrm{mg}$ of chlorothricolide methyl ester which was subjected to ${ }^{13} \mathrm{C}$ NMR spectroscopic analysis. The results, as summarized in Table 1, show extensive labeling and ${ }^{13} \mathrm{C}-{ }^{13} \mathrm{C}$ coupling for all the acetate-derived carbon atoms, consistent with the expected metabolism of glycerol via pyruvate to acetylCoA. Some labeling is also seen in the two propionate units, indicating some entry of the labeled acetyl-CoA into the Krebs cycle. Significantly, C-22, $\mathrm{C}-23$ and $\mathrm{C}-24$ also showed enrichment, and the signals for $\mathrm{C}-22$ and $\mathrm{C}-24$ displayed prominent ${ }^{13} \mathrm{C}-{ }^{13} \mathrm{C}$ couplings of $37.0 \mathrm{~Hz}$ and $51.3 \mathrm{~Hz}$, respectively (Fig. 1). These two carbons cannot couple to $\mathrm{C}-21$ and $\mathrm{C}-25$, respectively, because those carbons exhibit different coupling constants $\left({ }^{1} J_{\mathrm{cc}} 34.0 \mathrm{~Hz}\right.$ for $\mathrm{C}-21$ and $91.3 \mathrm{~Hz}$ for $\mathrm{C}-25$ ). The signal for $\mathrm{C}-23$ is rather weak and its coupling pattern is barely discernible; however, it is consistent with simultaneous coupling to two other carbon atoms. That C-23 is indeed coupled to both C-22 and C-24 was confirmed unequivocally by irradition of its signal at $80.6 \mathrm{ppm}$, which resulted in collapse of the signals for C-22 and C-24 into singlets*. Hence, glycerol is incorporated as an intact 3-carbon unit into C-22, C-23 and C-24.

To obtain further information on the orientation of the glycerol molecule in the 3-carbon moiety of II, we labeled glycerol stereospecifically in the pro- $R$ hydroxymethyl group. This is the carbon atom of glycerol at which phosphorylation takes place during metabolism, and which ultimately gives rise to $\mathrm{C}-3$ of triose phosphates, 3-phosphoglyceric acid and phosphoenolpyruvate. $(2 R)-\left[1-{ }^{2} \mathrm{H}_{2}\right]-$

\footnotetext{
* This irradiation experiment was kindly carried out for us by Prof. DAvID E. CANE at Brown University.
} 
Fig. 2. ${ }^{2} \mathrm{H}$ NMR spectrum of chlorothricolide derived from $(2 R)-\left[1-{ }^{2} \mathrm{H}_{2}\right]$ glycerol.

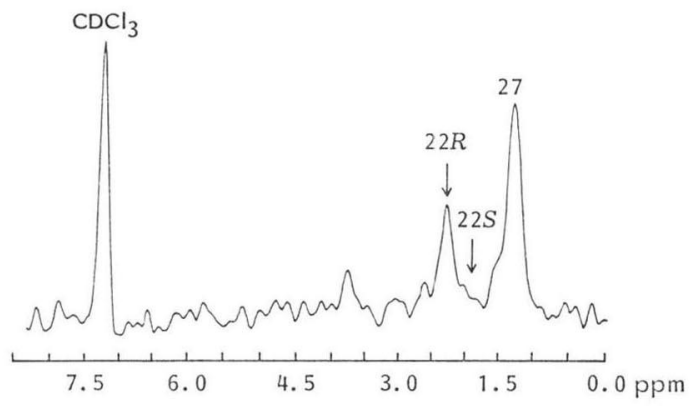

Glycerol $\left(98 \%\right.$ D) was prepared by $\mathrm{LiAl}^{2} \mathrm{H}_{4}$ reduction of 2,3-isopropylidene-D-glyceric acid ethyl ester followed by deprotection ${ }^{8)}, *$ This material (650 mg, $6.77 \mathrm{mmol}$ ) was fed to ten 100-ml cultures of $S$. antibioticus Tü 99, which were harvested 24 hours later and worked up to give $95 \mathrm{mg}$ I. Methanolysis of this material produced $29.5 \mathrm{mg}$ chlorothricolide methyl ester which was analyzed by deuterium NMR spectroscopy. The spectrum (Fig. 2) displays prominent signals at $1.35 \mathrm{ppm}(\mathrm{H}-27)$ and 2.33

$(\mathrm{H}-22 R)$. No signal was seen at the resonance frequency for $\mathrm{H}-22 S(1.78 \mathrm{ppm})$. The proton signal assignments for H-22R and H-22S were made by single frequency decoupling experiments, connecting H-29, H-21 and the two C-22 hydrogens. From the results it follows unequivocally that C-1 of glycerol (the pro- $R$ hydroxymethyl group) gives rise to C-22 of II, i.e., this carbon corresponds to $\mathrm{C}-3$ of a triose, that only one atom of deuterium from glycerol is retained in this position, and that this hydrogen occupies the $22 R$ position.

Origin of the Propionate Units

In an attempt to gain further insight into the mode of assembly of II, we examined the fate of the methyl hydrogen atoms of acetate in the biosynthesis by feeding ${ }^{13} \mathrm{C}^{2} \mathrm{H}_{3} \mathrm{COONa}$. The product $\mathbf{I}$ was converted to chlorothricolide methyl ester which was then analyzed by ${ }^{13} \mathrm{C}\left({ }^{1} \mathrm{H},{ }^{2} \mathrm{H}\right)$ triple resonance NMR spectroscopy ${ }^{\text {) }}$. Surprisingly, the results (data not shown) indicated no significant incorporation of deuterium into any of the positions derived directly from acetate. The only carbon showing any significant deuterium retention, relative to ${ }^{13} \mathrm{C}$, was $\mathrm{C}-27$, the methyl group derived from one of

Scheme 3. Pathways from ${ }^{13} \mathrm{C}^{2} \mathrm{H}_{3} \mathrm{COONa}$ to propionate units.

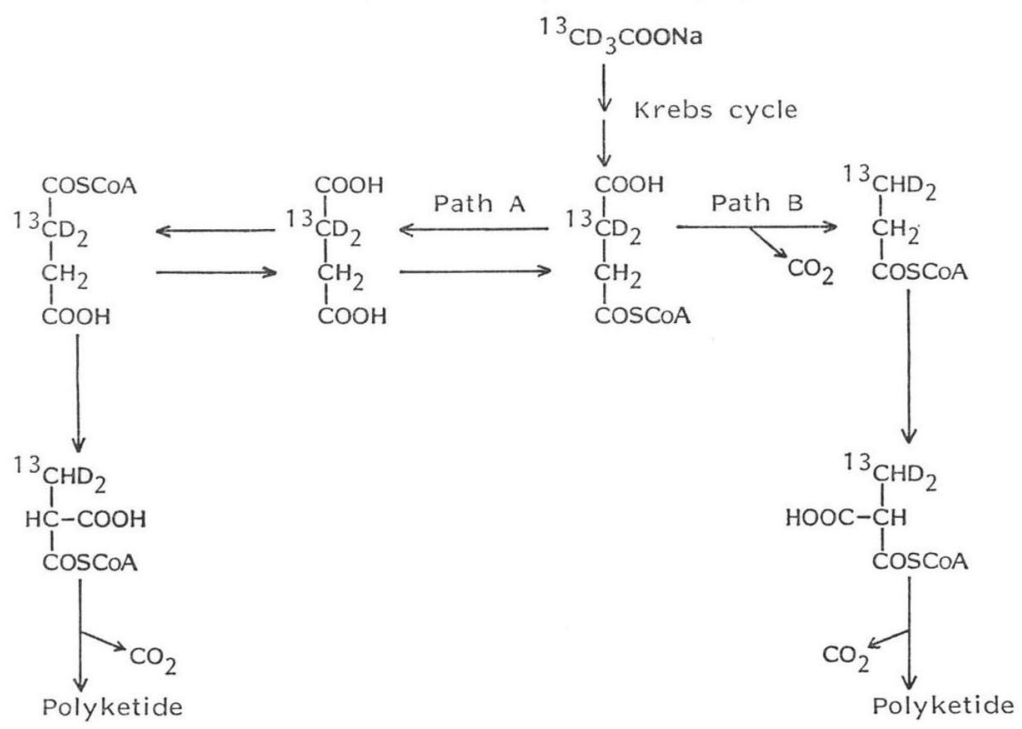

* We thank Dr. C. P. Gorst-Allman for this preparation. 
the two propionate units. Equally surprisingly, deuterium was present at this carbon almost exclusively ( $>80 \%$ ) in the form of $\mathrm{C}^{2} \mathrm{H}_{2}{ }^{1} \mathrm{H}$ groups; both mono-deuterated and tri-deuterated species were below the limit of detection (about 10\%). By the generally accepted route to "propionate units", rearrangement of succinyl-CoA to methylmalonyl CoA, di-deuterated methyl groups can only arise from ${ }^{13} \mathrm{C}^{2} \mathrm{H}_{3} \mathrm{COONa}$ if succinyl-CoA and free succinate are readily interconverted (Scheme 3). In view of the high efficiency of formation of di-deuterated methyl groups in the propionate unit, we considered the possible operation of an alternate pathway, by which succinyl-CoA is decarboxylated directly to propionyl-CoA. While mechanistically not particularly attractive, such a conversion would explain the predominant retention of two atoms of deuterium at C-27.

As a specific probe designed to distinguish between these two possible routes to propionate units we synthesized $\left[1,2-{ }^{13} \mathrm{C}_{2}\right]$ succinic acid. The rationale for the choice of this particular labeled precursor

Scheme 4. Expected coupling pattern in propionate units formed from $\left[1,2-{ }^{13} \mathrm{C}_{2}\right]$ succinate via methylmalonyl-CoA mutase and by direct decarboxylation of succinyl-CoA.

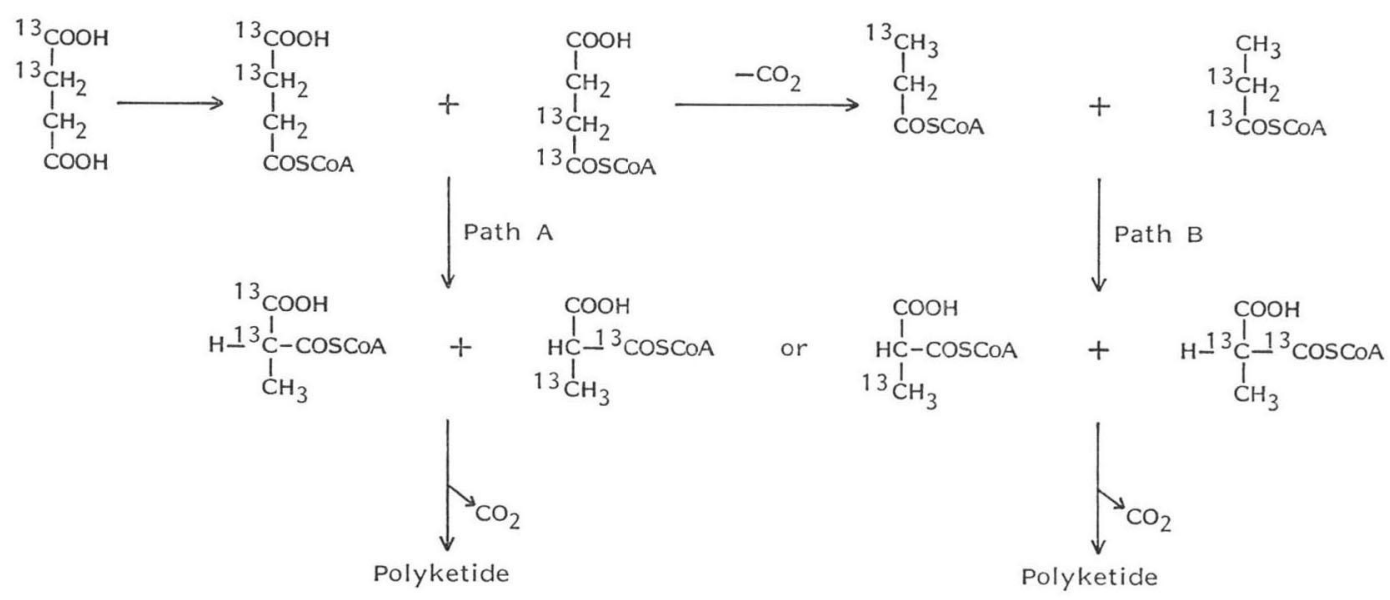

Prediction: No one-bond ${ }^{13} \mathrm{C}-{ }^{13} \mathrm{C}$ coupling.

One-bond ${ }^{13} \mathrm{C}-{ }^{13} \mathrm{C}$ coupling, C-1 $\leftrightarrow \mathrm{C}-2, \mathrm{C}-19 \leftrightarrow \mathrm{C}-20$.

Fig. 3. ${ }^{13} \mathrm{C}$ NMR signals for the carbon atoms of the two propionate units of chlorothricolide methyl ester derived from $\left[1,2-{ }^{13} \mathrm{C}_{2}\right]$ succinate.
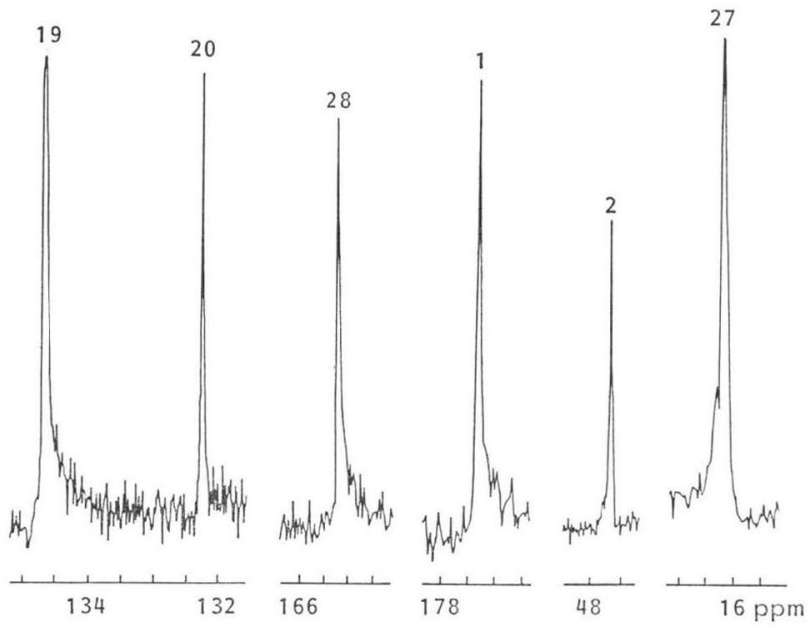
Scheme 5. Synthesis of D-[2- $\left.{ }^{2} \mathrm{H}\right] \mathrm{glucose}$.
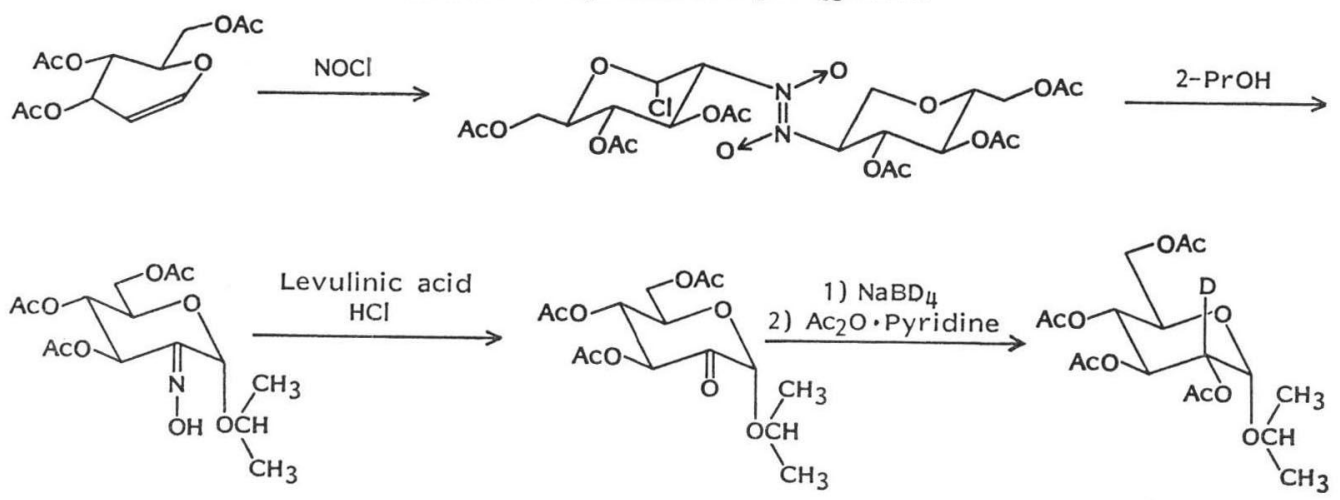

1) $\mathrm{CH}_{3} \mathrm{ONa}-\mathrm{CH}_{3} \mathrm{OH}$

2) $1 \mathrm{~N} \mathrm{CF}_{3} \mathrm{COOH}$

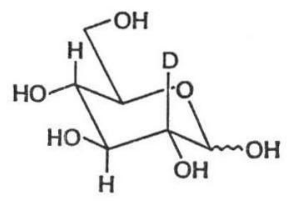

is evident from Scheme 4. By either route, all three carbon atoms of the propionate unit will be enriched, but the pathway via methylmalonyl-CoA mutase will result in no one-bond ${ }^{13} \mathrm{C}-{ }^{13} \mathrm{C}$ coupling in the product, whereas the direct decarboxylation of succinyl-CoA will result in one-bond coupling between carbons 1 and 2 of the propionate units in half the product molecules. The $\left[1,2-{ }^{13} \mathrm{C}_{2}\right]$ succinate (297 mg, 99\% ${ }^{13} \mathrm{C}$ ) was fed to ten cultures of S. antibioticus Tü 99 and the resulting I (153 mg) was degraded to give $59 \mathrm{mg}$ of chlorothricolide methyl ester for ${ }^{13} \mathrm{C}$ NMR analysis. The results indicated substantial enrichment of all the acetate- and propionate-derived carbon atoms, but no detectable onebond ${ }^{13} \mathrm{C}-{ }^{13} \mathrm{C}$ coupling for any of the signals. Scale expansions of the signals for all six carbon atoms of the two propionate units are shown in Fig. 3. It follows from this experiment that the propionate units are formed from succinate exclusively via the methylmalonyl-CoA mutase reaction.

\section{Stereochemistry of Removal of the 2-Hydroxyl Group of Glucose}

We had shown earlier ${ }^{7}$ that the conversion of glucose into the two 2,6-dideoxyhexose moieties of I involves a hexosenucleotide oxidoreductase reaction, probably TDP-glucose oxidoreductase, as the key step. This reaction eliminates the oxygen function from C-6 of the sugar. To gain more information on the biosynthetic conversion sequence, we examined the steric course of the replacement of the 2-hydroxyl group of glucose by hydrogen. To this end, $\left[2-{ }^{2} \mathrm{H}\right]$ glucose was synthesized as shown in Scheme $5^{10)}$. This material $\left(512 \mathrm{mg}, 2.83 \mathrm{mmol}, 98 \%{ }^{2} \mathrm{H}\right)$ together with $4.27 \mu \mathrm{Ci}$ of $\left[2-{ }^{3} \mathrm{H}\right] \mathrm{glucose}$

Scheme 6. Steric course of the conversion of D-[2- $\left.{ }^{2} \mathrm{H}\right]$ glucose into the 2-deoxy-D-rhamnose moieties of $\mathbf{I}$ by S. antibioticus Tü 99 .

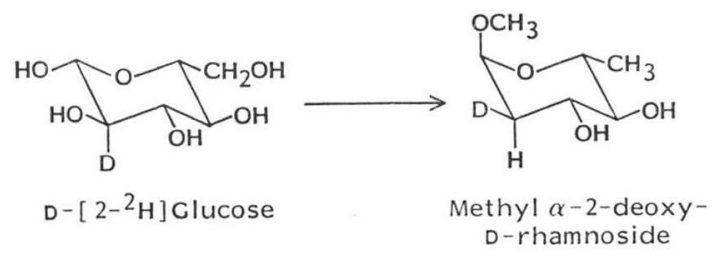

was fed to ten cultures of $S$. antibioticus Tü 99. The specific radioactivity of the isolated $\mathbf{I}(135 \mathrm{mg})$ corresponded to $2.6 \%$ deuterium enrichment. The ${ }^{1} \mathrm{H}$ NMR signals of the rhamnose moieties of $\mathbf{I}$ were partially assigned based on chemical shift theory, spin decoupling experiments and 2dimensional correlation spectroscopy. The ${ }^{2} \mathrm{H}$ NMR spectrum of the chlorothricin derived from $\left[2-{ }^{2} \mathrm{H}\right]$ glucose showed several signals, including 
Fig. 4. ${ }^{2} \mathrm{H}$ NMR spectrum of methyl $\alpha$-2-deoxy-D-rhamnoside from the degradation of I biosynthesized from $\left[2-{ }^{2} \mathrm{H}\right]$ glucose.

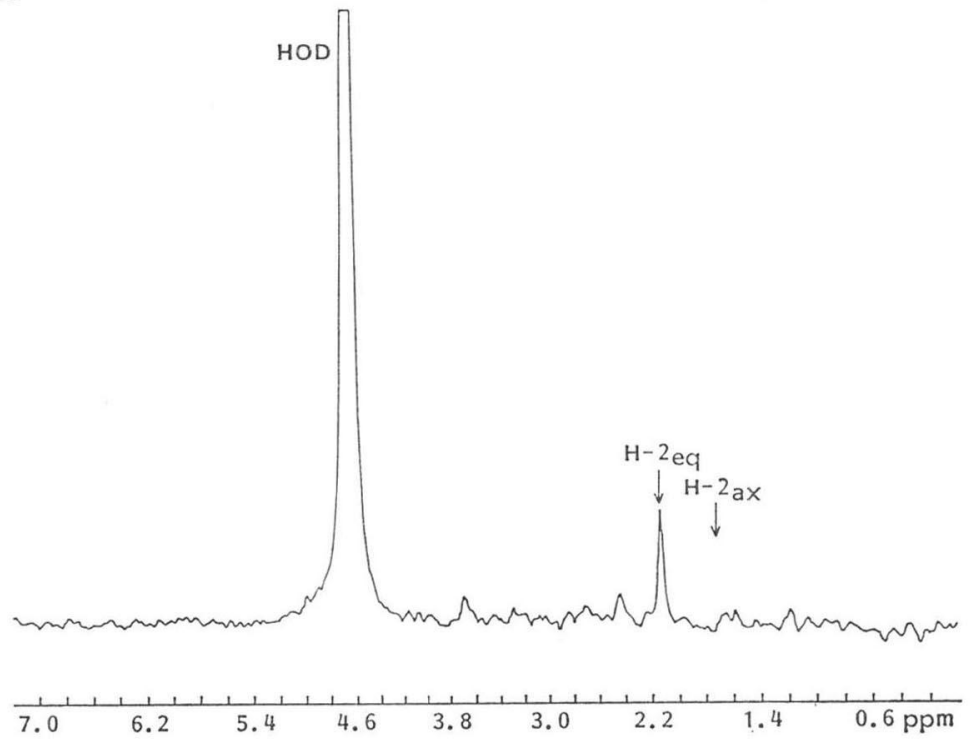

ones at 2.57 and $2.20 \mathrm{ppm}$, corresponding closely to the chemical shifts for $\mathrm{H}-2^{\prime \prime}{ }_{\mathrm{eq}}$ and $\mathrm{H}-2^{\prime \prime \prime}{ }_{\mathrm{eq}}$ of the two rhamnose moieties. This result was consistent with incorporation of $\mathrm{H}-2$ of glucose into the equatorial hydrogen at C-2 of the 2-deoxyrhamnose moiety, but did not prove that the label resided exclusively in that position.

The sample of I was therefore subjected to methanolysis and further degradation by alkaline hydrolysis to give $7 \mathrm{mg}$ of methyl $\alpha$-2-deoxy-D-rhamnoside. The ${ }^{2} \mathrm{H}$ NMR spectrum of this material showed virtually no signal other than the water peak. The feeding experiment was therefore repeated 3 times and all the samples of $\mathbf{I}$ were degraded to methyl $\alpha$-2-deoxy-D-rhamnoside. The pooled material gave a ${ }^{2} \mathrm{H}$ NMR spectrum (Fig. 4) which showed a single signal at $\delta 2.15$ ppm (HOD at 4.65 ppm) corresponding to $\mathrm{H}-2_{\mathrm{eq}}$ of methyl $\alpha$-2-deoxy-D-rhamnoside and no signal at the resonance frequency for $\mathrm{H}-2_{\mathrm{ax}}(1.71 \mathrm{ppm})$. Hence, the deuterium occupies the $\mathrm{H}-2 \mathrm{R}$ position and the conversion of glucose into the deoxyrhamnose moiety of I proceeds with inversion of configuration at C-2 of the sugar.

\section{Discussion}

The finding that glycerol rather than a 4-carbon dicarboxylic acid is an intact precursor of the C-22, C-23, C-24 moiety of chlorothricin leads us to propose a modification of our original hypothesis ${ }^{7)}$ for the assembly of the aglycone of $\mathbf{I}$ (Scheme 7). Of the various metabolites which can arise from glycerol, several (e.g., pyruvate, lactate) were ruled out as immediate precursors of the 3-carbon unit by radioactive tracer experiments. Among the remaining ones phosphoenolpyruvate seems the most attractive one mechanistically. Condensation with the penultimate carbon atoms at the two ends of the polyketide chain leads to a carbocyclic intermediate carrying a double bond between C-21 and C22 (Scheme 7). If the cyclizations to close the 6-membered ring occur before this double bond is reduced, the hydrogen addition to the double bond must be anti because the double bond in a 6-membered ring, of necessity, must have $Z$ configuration. If the double bond is reduced before ring closure, both $Z$ and $E$ configuration and hence, both syn and anti hydrogen addition are possible. The feature of Baeyer-Villiger oxidation as a late step converting the acyltetronic acid into the macrocyclic lactone structure (Scheme 7), proposed earlier ${ }^{7)}$, is strongly supported by the recent isolation of antibiotics, the tetrocarcins ${ }^{11,12)}$ and the kijanimicins ${ }^{13 \sim 15)}$ which retain the acyltetronic acid structure. 
Scheme 7. Hypothetical scheme for the formation of the aglycone moiety of chlorothricin.

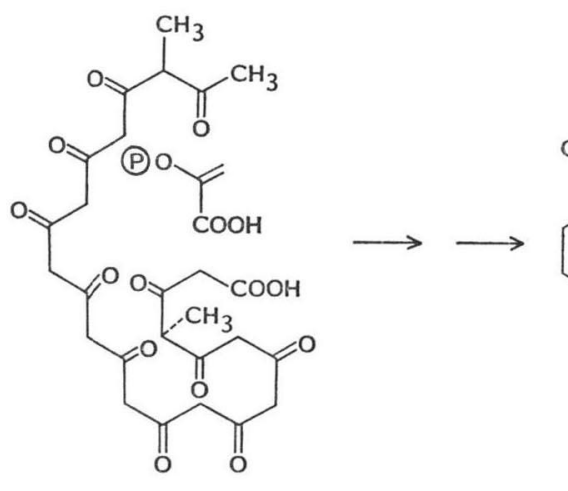<smiles>CC(=O)C(C)C(=O)CC(=O)CCCCCC1C=CC2C(O)CCCC2C1(C)C(=O)C(C(=O)O)C(=O)OCC(=O)CC(C)C(C)C(=O)O</smiles>

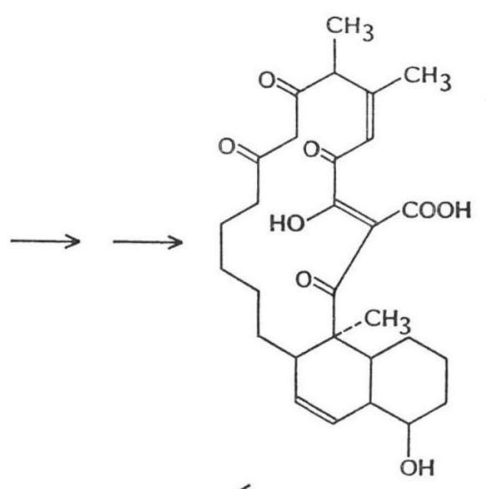

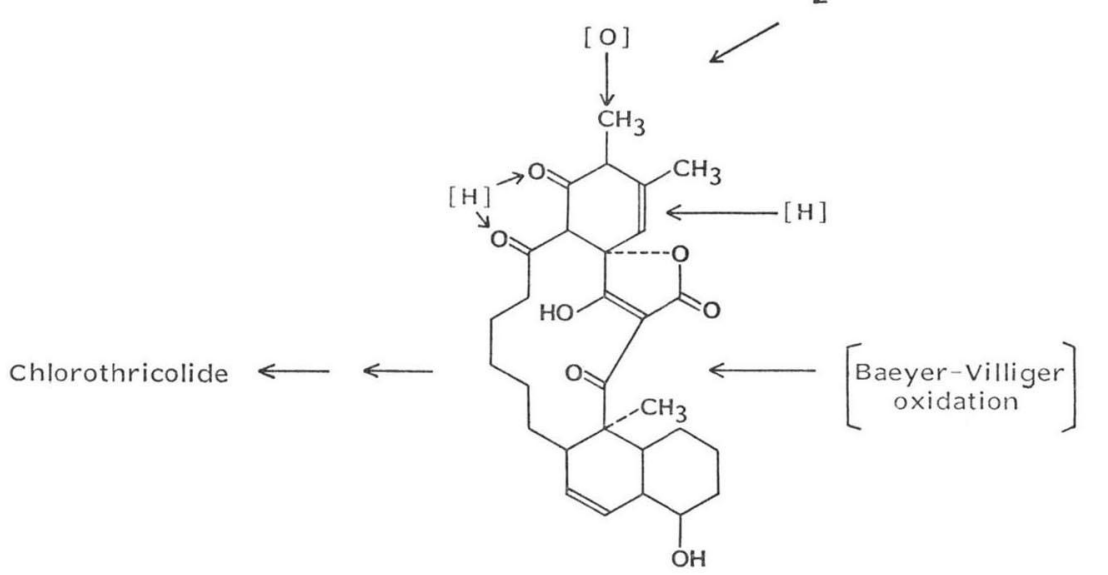

The peculiar finding that feeding of ${ }^{13} \mathrm{C}^{2} \mathrm{H}_{3} \mathrm{COONa}$ deuterium-labeled almost exclusively the propionate-derived methyl group, C-27, of I, generating predominantly ${ }^{13} \mathrm{CH}^{2} \mathrm{H}_{2}$ methyl groups, led us to suspect the operation of an unusual pathway for the formation of propionate units, direct decarboxylation of succinyl-CoA to propionyl-CoA. However, no evidence for such a metabolic route was uncovered by the feeding experiment with $\left[1,2-{ }^{13} \mathrm{C}_{2}\right]$ succinate designed specifically to probe this question. Rather, the results are entirely consistent with formation of the propionate units via the methylmalonyl-CoA mutase reaction, and the ${ }^{13} \mathrm{CH}^{2} \mathrm{H}_{2}$ methyl groups must arise from $\left[2-{ }^{13} \mathrm{C},{ }^{2} \mathrm{H}_{3}\right]-$ acetate via extensive interconversion between succinyl-CoA and free succinate. The results give no indication whether the recently discovered ${ }^{18)}$ pathway valine or butyrate $\rightarrow$ isobutyrate $\rightarrow$ methylmalonyl-CoA $\rightarrow$ propionate units is also operative.

The result of the stereochemical analysis of 2,6-dideoxyhexose formation was rather surprising in that it showed replacement of the 2-hydroxyl group of glucose by hydrogen with inversion. In earlier work we had examined the analogous question in the formation of the 2,6-dideoxyhexose moiety of the antibiotic granaticin, and had found ${ }^{17}$ ) that the reaction proceeds with retention of configuration at $\mathrm{C}-2$ of the sugar. The observation that the formation of two 2,6-dideoxyhexoses proceeds with different stereochemistry at $\mathrm{C}-2$ in the replacement of $\mathrm{OH}$ by $\mathrm{H}$ suggests that more than one pathway operates in the formation of these sugars.

\section{Experimental}

General Methods

Feeding experiments with $S$. antibioticus strain Tü 99 were carried out in 500-ml Erlenmeyer flasks 
containing $100 \mathrm{ml}$ of culture medium as described earlier ${ }^{7)}$. The isolation of chlorothricin, the methanolysis and the isolation of chlorothricolide methyl ester as well as methyl 2,6-dideoxy-D-rhamnoside also followed previously described procedures ${ }^{1,6,7)}$. NMR spectra were recorded on a Bruker WM300 FT NMR spectrometer operating at $7.1 \mathrm{~T}$.

Materials

$\left[U^{-13} \mathrm{C}_{3}\right] \mathrm{G}$ lycerol ${ }^{18,19)}$ and $(2 R)-\left[1-{ }^{2} \mathrm{H}_{2}\right]$ glycerol $^{8)}$ were synthesized by adaptations of literature methods. $\left[2-{ }^{14} \mathrm{C}\right]$ Glycerol and $\left[2-{ }^{3} \mathrm{H}\right]$ glucose were obtained from Amersham-Searle.

\section{$\left[1,2-{ }^{13} \mathrm{C}_{2}\right]$ Succinic Acid ${ }^{19,20)}$}

Trifluoroacetic acid anhydride $(8.16 \mathrm{~g}, 71.5 \mathrm{mmol})$ was carefully added to $\left[1,2-{ }^{13} \mathrm{C}_{2}\right]$ acetic acid $(1 \mathrm{~g}$, $16.13 \mathrm{mmol}, 99 \%{ }^{13} \mathrm{C}$ ) containing $127 \mathrm{mg}$ of $\mathrm{H}_{2} \mathrm{O}$. Phosphorous tribromide $(72.7 \mathrm{mg}, 0.27 \mathrm{mmol}$ ) was added to the mixture, which was then heated in an oil bath of $60^{\circ} \mathrm{C}$ under a dry ice condenser. Bromine ( $2.62 \mathrm{~g}, 16.4 \mathrm{mmol}$ ) was slowly added to the refluxing mixture at such a rate that a pale bromine color was just maintained. After the bromine addition was complete the mixture was cooled and $\mathrm{H}_{2} \mathrm{O}$ $(614 \mathrm{mg})$ was added. Trifluoroacetic acid and hydrogen bromide were removed by distillation. The residue of bromoacetic acid ( $2.08 \mathrm{~g}, 90 \%$ yield) solidified upon cooling.

Diethyl malonate $(2.40 \mathrm{~g}, 15 \mathrm{mmol})$ was slowly added to sodium ethoxide freshly prepared from $7.3 \mathrm{ml}$ of dry EtOH and sodium metal (333 mg, $14.5 \mathrm{~m}$ atom). $\left[1,2-{ }^{13} \mathrm{C}_{2}\right]$ Bromoacetic acid $(2 \mathrm{~g}, 14.2$ $\mathrm{mmol}$ ) was converted to the methyl ester with diazomethane in ether, and the ether solution was added to the refluxing solution of sodium diethyl malonate in $\mathrm{EtOH}$. The mixture was heated under reflux for 5 hours, sodium bromide was removed by filtration and the filtrate was partitioned between $\mathrm{H}_{2} \mathrm{O}$ and ether. The combined organic extract was dried $\left(\mathrm{MgSO}_{4}\right)$, the ether evaporated and the residue saponified with $\mathrm{KOH}(5 \mathrm{~g})$ in aq EtOH $\left(3 \mathrm{ml} \mathrm{EtOH}, 2 \mathrm{ml} \mathrm{H}_{2} \mathrm{O}\right)$. The EtOH and $\mathrm{MeOH}$ were distilled off and $10 \mathrm{~g}$ conc sulfuric acid were added to the reaction mixture, which was then heated under reflux for 3 hours. After cooling the succinic acid was extracted continuously with ether overnight and recrystallized from EtOAc. Yield of $\left[1,2-{ }^{13} \mathrm{C}_{2}\right]$ succinic acid $865 \mathrm{mg}(50.7 \%)$ : MP $181 \sim 182{ }^{\circ} \mathrm{C} ;{ }^{1} \mathrm{H}$ NMR (acetone- $\left.d_{6}\right) \delta 9.36\left(2 \mathrm{H}\right.$, br s), $2.59\left(2 \mathrm{H}, \mathrm{ddt},{ }^{1} J_{\mathrm{CH}}=129.8 \mathrm{~Hz}\right), 2.59(2 \mathrm{H}$, ddt).

\section{$\left[2-{ }^{2} \mathrm{H}\right] \mathrm{Glucos}^{10)}$}

Dry 3,4,6-tri- $O$-acetyl-D-glucal $(12 \mathrm{~g}, 44.1 \mathrm{mmol})$ was dissolved in $10 \mathrm{ml}$ of EtOAc. Nitrosyl chloride was slowly introduced over the solution with stirring and cooling to $-5^{\circ} \mathrm{C}$. After an excess of the gas had been introduced, stirring was continued until the reaction was complete as judged by TLC (silica gel, EtOAc - hexane, $1: 1$ ). The solvent was removed and the residue was crystallized from $\mathrm{CHCl}_{3}$ - hexane to give $12.2 \mathrm{~g} \mathrm{(82 \% )}$ ) of 3,4,6-tri- $O$-acetyl-2-deoxy-2-nitroso- $\alpha$-D-glucopyranosyl chloride, $\mathrm{mp} 125 \sim 127^{\circ} \mathrm{C}$ (literature $129 \sim 130^{\circ} \mathrm{C}$ ).

A solution of the above compound $(10.5 \mathrm{~g}, 31.3 \mathrm{mmol})$ and $2.08 \mathrm{ml}$ dry 2-propanol in $15 \mathrm{ml}$ of anhydrous methylene chloride was gently refluxed with exclusion of moisture until the evolution of $\mathrm{HCl}$ ceased. The solvent was distilled off and the residue crystallized from 2-propanol to give $7.9 \mathrm{~g}$ $(70.3 \%)$ of isopropyl 3,4,6-tri- $O$-acetyl-2-oximino- $\alpha$-D-arabinohexopyranoside, $\mathrm{mp} 86 \sim 90^{\circ} \mathrm{C}$.

A mixture of the above compound $(5.05 \mathrm{~g}, 14 \mathrm{mmol}), 9.31 \mathrm{ml}$ of glacial acetic acid, $8.14 \mathrm{~g}$ of levulinic acid and $14 \mathrm{ml}$ of $1 \mathrm{~N} \mathrm{HCl}$ was stirred overnight at room temp. Methylene chloride was added to the reaction mixture and the organic layer was washed with $\mathrm{H}_{2} \mathrm{O}$ and then with $\mathrm{NaHCO}_{3}$ solution. After drying the solvent was evaporated and the residue dissolved in $6.5 \mathrm{ml}$ of dioxane and $6.5 \mathrm{ml}$ of deuterium oxide. A cold solution of $0.95 \mathrm{~g}$ of sodium borodeuteride in $4 \mathrm{ml}$ of dioxane $-{ }^{2} \mathrm{H}_{2} \mathrm{O}(1: 1)$ was added dropwise with stirring and cooling to $5^{\circ} \mathrm{C}$; stirring was continued for 2 hours at room temp. The excess $\mathrm{NaB}^{2} \mathrm{H}_{4}$ was destroyed with acetic acid and the solvents were distilled off. The dried residue was acetylated overnight with $8.2 \mathrm{ml}$ pyridine and $9.5 \mathrm{ml}$ acetic anhydride. The reaction mixture was poured into ice water and the product extracted with methylene chloride. The organic phase was washed successively with $1 \mathrm{~N} \mathrm{H}_{2} \mathrm{SO}_{4}, \mathrm{H}_{2} \mathrm{O}$ and $\mathrm{NaHCO}_{3}$ solution and dried $\left(\mathrm{Na}_{2} \mathrm{SO}_{4}\right)$. The solution was concentrated to a syrup which was crystallized from aq EtOH to give $3.2 \mathrm{~g}(58.6 \%)$ of isopropyl 2,3,4,6-tetra- $O$-acetyl- $\alpha$-D-[2- $\left.{ }^{2} \mathrm{H}\right]$ glucopyranoside: $\mathrm{MP} 79 \sim 82^{\circ} \mathrm{C}$; $[\alpha]_{\mathrm{D}}^{24}+148.5^{\circ}\left(c \mathrm{1.47}, \mathrm{CHCl}_{3}\right)$, (literature $\left.+144.5^{\circ}, c 1.6, \mathrm{CHCl}_{3}\right) ;{ }^{1} \mathrm{H}$ NMR $\left(\mathrm{CDCl}_{3}\right) \delta 5.44(1 \mathrm{H}, \mathrm{d}, J=9 \mathrm{~Hz}, \mathrm{H}-3), 5.13(1 \mathrm{H}, \mathrm{s}, \mathrm{H}-1), 4.99$ 
$(1 \mathrm{H}, \mathrm{t}, J=9 \mathrm{~Hz}, \mathrm{H}-4), 3.69 \sim 4.33(4 \mathrm{H}, \mathrm{m}), 2.04(\mathrm{~s}), 1.99(\mathrm{~s}), 1.98(\mathrm{~s}), 1.22(3 \mathrm{H}, \mathrm{d}, J=6.1 \mathrm{~Hz}), 1.11(3 \mathrm{H}$, d, $J=6.1 \mathrm{~Hz})$.

The above compound $(3.12 \mathrm{~g}, 8 \mathrm{mmol})$ was stirred in a freshly prepared solution of sodium methoxide ( $37.4 \mathrm{mg}$ of sodium metal in $10 \mathrm{ml}$ of $\mathrm{MeOH}$ ) for 1 hour at room temp. Sodium ions were removed by passage through a column of cation exchange resin (Dowex 50WX8, $\mathrm{H}^{+}$), then solvent was evaporated in a rotary evaporator at below $30^{\circ} \mathrm{C}$. The resulting yellowish syrup was hydrolyzed with $40 \mathrm{ml}$ of $1 \mathrm{~N}$ trifluoroacetic acid under reflux for 5 hours. After decolorization with activated charcoal, $\mathrm{H}_{2} \mathrm{O}$ was removed by lyophilization to give $1.38 \mathrm{~g}(96 \%)$ of $\left[2-{ }^{2} \mathrm{H}\right]$ glucose. ${ }^{1} \mathrm{H}$ NMR $\left(\mathrm{D}_{2} \mathrm{O}\right)$ $\delta 5.12(0.35 \mathrm{H}, \mathrm{s}, \mathrm{H}-1$ of $\alpha$-D-glucose $), 4.53(0.65 \mathrm{H}, \mathrm{s}, \mathrm{H}-1$ of $\beta$-D-glucose).

\section{Acknowledgments}

We thank Dr. C. P. Gorst-Allman for the preparation of $(2 R)-\left[1-{ }^{2} \mathrm{H}_{2}\right]$ glycerol, Prof. D. E. CANE, Brown University, for the ${ }^{13} \mathrm{C}$-homonuclear decoupling experiment, and the Los Alamos Stable Isotope Resource (supported by NIH grant RR 02231) for ${ }^{13} \mathrm{C}$-labeled material. Support of this work by the National Institutes of Health through research grant AI 20264 is gratefully acknowledged.

\section{References}

1) Keller-Schierlein, W.; R. Muntwyler, W. Pache \& H. Zähner: Stoffwechselprodukte von Mikroorganismen. Chlorothricin und Deschlorothricin. Helv. Chim. Acta 52: 127 142, 1969

2) Muntwyler, R.; J. Widmer \& W. Keller-Schierlein: Stoffwechselprodukte von Mikroorganismen. Synthese des 5-Chlor-6-methylsalicylsäure-methyläthers, eines Abbauproduktes des Chlorothricins. Helv. Chim. Acta. 53: 1544 1547, 1970

3) Muntwyler, R. \& W. Keller-Schierlein: Stoffwechselprodukte von Mikroorganismen. Die Struktur des Chlorothricins, eines neuartigen Makrolid-Antibioticums. Helv. Chim. Acta 55: 2071 2094, 1972

4) Brufani, M.; S. Cerrini, W. Fedeli, F. Mazza \& R. Muntwyler: Stoffwechselprodukte von Mikroorganismen. Kristallstrukturanalyse des Chlorothricolid-methylesters. Helv. Chim. Acta 55: 2094 2102, 1972

5) Gerhard, A.; R. Muntwyler \& W. Keller-Schierlein: Stoffwechselprodukte von Mikroorganismen. Über eine unerwartete Umwandlung in der Chlorothricin-Reihe. Helv. Chim. Acta 58: 1323 1338, 1975

6) Holzbach, R.; H. Pape, D. Hook, E. F. Kreutzer, C.-J. Chang \& H. G. Floss: Biosynthesis of the macrolide antibiotic chlorothricin: Basic building blocks. Biochemistry 17: 556 560, 1978

7) Mascaretti, O. A.; C.-J. Chang, D. Hook, H. Otsuka, E. F. Kreutzer \& H. G. Floss: Biosynthesis of the macrolide antibiotic chlorothricin. Biochemistry 20: 919 924, 1981

8) BAer, E. \& H. O. Fischer: Studies on acetone-glyceraldehyde. IV. Preparation of d $(+)$-acetone glycerol. J. Biol. Chem. 128: 463 473, 1939

9) McInnes, A. G.; J. A. Walter \& J. L. C. Wright: Differential hydrogen exchange during the biosynthesis of fatty acids in Anacystis nidulans: The incorporation of $\left[2,2,2-{ }^{2} \mathrm{H}_{3}, 2-{ }^{13} \mathrm{C}_{0 ; 1}\right]$ acetate. Tetrahedron Lett. 1979: 3245 3248, 1979

10) Lemieux, R. U. \& T. L. Nagabhushan: cis-1,2-Glycosides. Meth. Carbohydr. Chem. 6: 487 495, 1975

11) Tоміта, F. \& T. Tамаокі: Tetrocarcins, novel antitumor antibiotics. I. Producing organism, fermentation and antimicrobial activity. J. Antibiotics 33: 940 945, 1980

12) Hirayama, N.; M. Kasai, K. Shirahata, Y. Ohashi \& Y. Sasada: The Structure of tetronolide, the aglycone of antitumor antibiotic tetrocarcin. Tetrahedron Lett. 21: 2559 2560, 1980

13) Mallams, A. K.; M. S. Puar \& R. R. Rossman: Kijanimicin. 1. Structures of the individual sugar components. J. Am. Chem. Soc. 103: 3938 3940, 1981

14) Mallams, A. K.; M. S. Puar, R. R. Rossman, A. T. McPhail \& R. D. Macfarlane: Kijanimicin. 2. Structure and absolute stereochemistry of kijanimicin. J. Am. Chem. Soc. 103: 3940 3943, 1981

15) Mallams, A. K.; M. S. Puar, R. R. Rossman, A. T. McPhail, R. D. Macfarlane \& R. L. Stephens: Kijanimicin. Part 3. Structure and absolute stereochemistry of kijanimicin. J. Chem. Soc. Perkin Trans. I 1983: $1497 \sim 1534,1983$

16) Gani, D.; D. O'Hagan, K. Reynolds \& J. A. Robinson: Biosynthesis of the polyether antibiotic monensin-A: Stereochemical aspects of the incorporation and metabolism of isobutyrate. J. Chem. Soc. Chem. Commun. 1985: 1002 1004, 1985 
17) Snipes, C. E.; C.-J. Chang \& H. G. Floss: Biosynthesis of the antibiotic granaticin. J. Am. Chem. Soc. 101: $701 \sim 706,1979$

18) Отт, D. G.: Synthesis with Stable Isotopes of Carbon, Nitrogen and Oxygen. pp. 33 35, 37, John Wiley \& Sons, New York, 1981

19) Murray, A. W. \& D. L. Williams: Organic Synthesis with Isotopes. pp. 931 932, Interscience, New York, 1958

20) Roberts, J. L. \& C. D. Poulter: $2^{\prime}, 3^{\prime}, 5^{\prime}-$ Tri- $O$-benzoyl $\left[4-{ }^{13}\right.$ C $]$ uridine. An effective, regiospecific synthesis of the pyrimidine ring. J. Org. Chem. 43:1547 1550, 1978 